\title{
Os significados e sentidos de ensino: o ensino eclético
}

\author{
The meanings and the senses of teaching: eclectic teaching \\ Los significados y los sentidos de la enseñanza: enseñanza eclética
}

Recebido: 19/10/2021 | Revisado: 27/10/2021 | Aceito: 10/11/2021 | Publicado: 14/11/2021

\author{
Carlos José de Sousa Carneiro \\ ORCID: https://orcid.org/0000-0001-6267-6127 \\ Secretaria Estadual de Educação do Piauí. Brasil \\ E-mail: casesofia07setembro@gmail.com
}

\begin{abstract}
Resumo
O presente artigo é consequência da pesquisa de Mestrado em Educação na Universidade Federal do Piauí. Investiga os sentidos e significados de ensino desenvolvidos por professores de uma escola pública estadual de Ensino Médio na cidade de Parnaíba, estado do Piauí. Neste trabalho, apresentamos um dos significados de ensino, o Ensino Eclético, o que representa o ponto alto da investigação e da produção do conhecimento. A pesquisa contou com as categorias teóricas de Significado e Sentido em Vigotski $(2008,2007,2000)$ e com o procedimento da entrevista reflexiva em Szimanski (2010). Na análise, descobrimos que o Ensino Eclético não encontra atributos em teorias e/ou bibliografias ricas, tendo os seus atributos construídos durante a pesquisa a partir da empiria e da experiência dos professores envolvidos na pesquisa.
\end{abstract}

Palavras-chave: Ensino; Significados e sentidos; Ensino eclético.

\begin{abstract}
This article is a consequence of research for a Masters in Education at the Federal University of Piauí. It investigates the senses and meanings of teaching developed by teachers of a state public high school in the city of Parnaíba, state of Piauí. In this work, we present one of the meanings of teaching, Eclectic Teaching, which represents the high point of research and knowledge production. The research included the theoretical categories of Meaning and Meaning in Vygotski $(2008,2007,2000)$ and the reflective interview procedure in Szimanski (2010). In the analysis, we found that Eclectic Teaching does not find attributes in theories and/or rich bibliographies, having its attributes built during the research based on the empirical and experience of the teachers involved in the research.
\end{abstract}

Keywords: Teaching; Meanings and senses; Eclectic teaching.

\section{Resumen}

Este artículo es consecuencia de una investigación para una Maestría en Educación de la Universidad Federal de Piauí. Investiga los sentidos y significados de la enseñanza que desarrollan los docentes de una escuela secundaria pública estatal en la ciudad de Parnaíba, estado de Piauí. En este trabajo presentamos uno de los significados de la docencia, la Enseñanza Ecléctica, que representa el punto culminante de la investigación y la producción de conocimiento. La investigación incluyó las categorías teóricas de Significado y Significado en Vygotski (2008, 2007, 2000) y el procedimiento de entrevista reflexiva en Szimanski (2010). En el análisis, encontramos que la Enseñanza Ecléctica no encuentra atributos en teorías y/o bibliografías ricas, teniendo sus atributos construidos durante la investigación a partir de la experiencia y empírica de los docentes involucrados en la investigación.

Palabras clave: Enseñando; Significados y sentidos; Enseñanza eclética.

\section{Introdução}

O presente artigo científico é consequência da pesquisa de Mestrado em Educação pelo Programa de Pós-Graduação em Educação da Universidade Federal do Piauí concluído em 2017. Na ocasião, pesquisamos os significados e sentidos de ensino desenvolvidos por professores do Ensino Médio de uma escola pública estadual da cidade de Parnaíba, litoral do Piauí. Contando com a voluntária adesão de 3 professores com formação em Licenciatura, utilizamos questionário e entrevista reflexiva para coletar os dados a serem analisados e responder à questão da pesquisa: quais os significados e sentidos de ensino desenvolvidos por professores do Ensino Médio de uma escola pública estadual em Parnaíba?

Nesta produção, vamos nos atear à parte da pesquisa que analisa o significado e o sentido do Ensino Eclético, ponto alto da pesquisa, haja vista que há pouco conteúdo teórico e bibliográfico a esse respeito, sendo, portanto, mais encontrado na 
empiria dos professores por meio das suas falas do que por autores e/ou teóricos. É, pois, nesse sentido, a inovação no campo da descoberta científica e teórica a partir da pesquisa de Mestrado supracitada, pois, conforme Carneiro (2017, p. 60), “[...] a prática não é pura, mas uma hibridização [...]”. Assim, constitui avanço no campo da Educação capaz de criar as condições de compreensão desse significado de ensino por meio de abordagem científica.

Assim, o artigo ora desenvolvido se debruça sobre o contexto empírico dos professores analisado a partir dos procedimentos adotados e citados anteriormente no intuito de organizar o significado e do sentido do Ensino Eclético, construindo, durante o percurso da pesquisa de origem, os atributos do ensino eclético.

\section{Metodologia}

Levando em conta o objeto da pesquisa e do presente artigo, apresentamos o percurso teórico-metodológico adotado, escolha feita à luz dos instrumentos e procedimentos capazes de nortear a pesquisa e colaborar para que os objetivos fossem atingidos, haja vista gerar as condições exigidas pela comunidade acadêmica e científica, quais sejam a teoria, os procedimentos e os critérios inspirados no materialismo histórico-dialético (Afanássiev, 1982), no questionário (Richardson, 1985) e na entrevista reflexiva (Szimanski, 2010). Na pesquisa, o arcabouço teórico-metodológico assumido foi capaz de viabilizar os caminhos seguidos para se alcançar os resultados e se chegar às conclusões.

O materialismo histórico-dialético é a lente pela qual estudamos e compreendemos a atividade de ensino sem desprezar a sua dinâmica real, vislumbrando o locus do professor na sua versão genuína, captando na empiria os atributos necessários e suficientes para a compreensão do significado e do sentido do Ensino Eclético. O questionário foi instrumento de base para a entrevista reflexiva, pois dimensionou aspectos da formação e da prática docente dos professores envolvidos na pesquisa. Foi, pois, a entrevista reflexiva que elevou a compreensão da atividade de ensino dos professores, por sua característica de criar as condições para espaço de debate e desenvolvimento da consciência da prática docente.

Nessa direção, esta pesquisa não desvincula teoria e metodologia, pois a natureza da investigação a partir do arcabouço teórico-metodológico ora apresentado mantém relação e ligação, constituindo-se uma lente uma que, bem direcionada e aplicada, foi capaz de responder à questão da pesquisa e construir, no desenvolvimento da investigação, os atributos do significado e do sentido do Ensino Eclético.

\section{Resultados e Discussão}

Considerando o contexto teórico metodológico da presente pesquisa, foi possível compreender o significado do Ensino Eclético. De acordo com Lima (s/d), o Ensino Eclético tem os primeiros registros na Itália, mais especificamente no século XIX, e é considerado "[...] global porque parte de um todo [...]" (Lima, s/d/, p. 1). Nessa direção, o significado do Ensino Eclético representa nos docentes a seleção do que parece ser melhor nos demais significados de ensino, sem contudo representar a totalidade de um ou de outro ensino.

O significado de Ensino Eclético, segundo Carneiro (2017, p. 52)

[...] contempla atributos que se confundem com os do Ensino Tradicional: a manutenção da disciplina em sala de aula, a relação hierárquica vertical entre professor e aluno, a preocupação com o ensino pragmático em detrimento da sua historicidade e criação das condições de transformação sócio-históricas. Assim, apresenta interesse pelos meios eficazes e eficientes para atingir o fim da atividade de ensino. Entretanto, não apresenta outros atributos, tal como o viés autoritário.

Nessa perspectiva, o significado de Ensino Eclético tem o professor como um facilitador da aprendizagem e não como transmissor de conteúdos, pois o conteúdo advém das próprias experiências dos alunos - característica do inatismo. "O 
professor não ensina, apenas cria condições para que os alunos aprendam” (Mizukami, 1986, p. 38). As experiências trazidas pelo aluno e reconstruídas por ele é que são os conteúdos da educação.

Os atributos desse significado de ensino são apresentados por Ibiapina (2007, p. 84), quando a autora afirma:

[...] o conhecimento não está associado ao processo de transmissão, mas à descoberta de respostas necessárias às exigências da vida social. Os professores não transmitem conhecimentos, apenas facilitam o acesso às informações necessárias à aquisição de saberes vinculados às realidades sociais do educando. Ensinar é processo em que os indivíduos se envolvem em diálogo constante com a realidade com finalidade de auto-aprendizagem. Ensinar é facilitar a busca pelo conhecimento, assim, aquisição de saberes é produção que ocorre a partir da autodeterminação do próprio aprendiz.

Nessa perspectiva, podemos entender que no significado de Ensino Eclético "[...] a realidade é algo subjetivo, um fenômeno reconstruído pelo sujeito a partir das suas percepções, recebendo as experiências e lhes atribuindo significado" (Carneiro, 2017, p. 52).

Assim compreendido o significado do Ensino Eclético, temos o professor como facilitador não autoritário, considerando que os próprios conteúdos de ensino são secundários em decorrência da valorização das relações entre as pessoas envolvidas no processo de ensino e aprendizagem.

Nesse contexto, entendemos o significado de Ensino Eclético com atributos limitados são formados e desenvolvidos segundo a atividade de ensino e a prática do professor, com vínculo na realidade.

Dado o exposto, é possível dimensionar o significado de Ensino Eclético como característico do professor facilitador do conhecimento e o aluno como centro do ensino, haja vista esse significado de ensino considerar "[...] o processo para atingir o produto da sua ação, ignorando o contexto sócio-histórico, visando à necessidade pragmática, imediata, o que, consequentemente, não cria as condições para a transformação do ensino e nem da realidade dos sujeitos envolvidos." (Carneiro, 2017, p. 53).

Nessa perspectiva, os excertos a seguir, construídos na e durante a entrevista reflexiva, demonstram as afirmações acima mencionadas. Trata-se de um dos professores envolvidos na pesquisa, o qual nomearemos de Professor H2. Vejamos:

Pesquisador: Nesse contexto, eu lhe pergunto: o que é ensino? Como você me reponde: o que é ensino?

Professor H2: Ensino... ô pergunta! Eu poderia tentar te responder o que é ensinar.

Pesquisador: Responda, então.

Professor H2: O ensino, o ensinar é tentar passar para alguém, tentar transferir um conhecimento para alguém que não o tem e que esse conhecimento possa fazer alguma diferença, alguma modificação na vida da pessoa que, em tese, deveria aprender.

Pesquisador: Esse ensino que o... como você fala... e você disse antes que depende do professor, ensinar é algo que é exclusivamente do professor, como você disse antes, eu pergunto agora: em algum momento, ele deixa de ser só do professor ou não?

Professor H2: A parte de ensinar?

Pesquisador: Sim.

Professor H2: Eu acredito piamente que o ensinar formal pertence ao professor, o ensinar formal.

Pesquisador: Ele não conta com nenhum outro elemento, nenhum outro personagem?

Professor H2: Como assim? 
Professor H2: Sim.

Pesquisador: Tem alguma influência, tem alguma importância no processo, na atividade de ensino?

Professor H2: Sim, no sentido de interagir, de sugar do professor tudo que ele tem para oferecer.

Pesquisador: Pode ser porque você falou de participação, anteriormente. Eu quero saber se essa participação influencia...

Professor H2: A participação que eu falei, no estímulo?

Pesquisador: Você disse que gosta de perguntar, que participem...

Professor H2: Sim, sim, sim. É, mas isso eu não classifico... Veja bem: a parte de interagir, de participar é aquilo que provoca o ato de ensinar, no que ele interage, no que ele participa, ele está demonstrando o polo da aprendizagem. Mas eu me refiro ao ensino formal. Aquele chavão do "nós vamos aprender um com o outro" diz respeito a outras coisas como os valores. Mas o ensino formal, parte de mim pra lá e dificilmente vem na direção contrária.

Levando em conta a fala do Professor H2 quanto ao ensino que desenvolve, o significado e o sentido dão condições para a compreensão de que a atividade de ensino apresenta ações de transmissão de conhecimento que conta com a participação do aluno e com o objetivo de transformar a vida dos sujeitos envolvidos, ainda que não seja suficiente para localizar essa mudança no contexto sócio-histórico, pois compreende o ensino sem conexão com a sua historicidade, sendo atividade estanque.

Nessa direção, o professor H2 evidencia que, para ele, o ensino é processo para produto, isto é, um meio para atingir um fim imediato, a-histórico, pragmático. Apresenta, pois, atributos do Ensino Eclético, entendendo-se facilitador do conhecimento e entendendo o aluno como centro da atividade de ensino, afirmando que o discente tem o interesse "[...] de sugar do professor tudo que ele tem pra oferecer." (Professor H2).

Com o objetivo de compreender o contexto da reflexão crítica, acerca da aula do professor H2, analisamos a sua compreensão pela fala a seguir:

Pesquisador: Entendi. Se você pudesse descrever uma aula sua no Ensino Médio, como seria? Descrever a aula.

Professor H2: Descrever a aula. Em todos os passos?

Pesquisador: Sim.

Professor H2: Chegaria, daria um bom dia, escreveria meu nome na lousa, dividiria o quadro em três partes, colocaria o tema do assunto, colocaria todos os tópicos que eu tinha preparado pra aula no quadro e, a partir daqueles tópicos, eu iria desenvolver uma conversa com eles e complementar os tópicos em seguida. Sugerir leituras e outras atividades complementares. Sempre que possível e conveniente tento quebrar o gelo da aula com algo leve ou engraçado.

Pesquisador: Mas é assim que você faz no Ensino Médio?

Professor H2: É assim que eu faço no Ensino Médio também. Minutos atrás eu havia dito, salvo engano, que as aulas para Fundamental e Médio são diferentes. Não é que eu esteja me contradizendo agora. Os passos são os mesmos, mas com uma complexidade discursiva maior.

Pesquisador: Então, continue. Diga como é que você faz. Além disso aí, o que é que você faz mais quando você ensina?

Professor H2: Bom, em resumo, seria isso. À medida que eu vou explicando o assunto, obviamente, eu peço pra eles abrirem o livro, colocar na página tal referente ao assunto e aí eu vou questionando, vou fazendo perguntas sobre esse ou aquele tópico... Bom, o que nós podemos enumerar? E aí eu chamo um aluno, chamo: "Zezinho, por 
gentileza, olha aí pra mim quais são as características do primeiro reinado, pois eu não as lembro”. Aí o Zezinho vai lá, lê e responde: "Professor, é assim, é assim, é assim". Na medida em que eu vou escrevendo, vou tecendo comentários sobre aquilo até chegar o final do que eu havia planejado. Chegando ao fim, pergunto: "Há alguma dúvida?". Bom, geralmente não há. Aí vem aquele velho dilema: não há porque entenderam tudo ou não há porque não entenderam nada?. A partir daí, se eu não conseguir findar o assunto todo, né?, eu digo: "Olha, continuaremos na próxima aula a partir daqui.". Caso eu tenha terminado, eu digo: "Agora, nós vamos fazer atividade na página tal e complementaremos com outras, se for possível.". "É sempre assim?” Você deve estar se perguntando. Não, não é sempre assim porque há inúmeros fatores que acontecem no dia a dia da sala de aula. Há dias que a turma permite você trabalhar com aquilo que você tinha planejado no dia anterior, mas há dias que a turma simplesmente não contribui. E aí são coisas bem subjetivas do tipo você chega numa turma e se depara com uma energia estranha. Você se pergunta: “Energia? Que tipo de energia você está falando, [Professor H2]?”. É um astral, uma atmosfera que te joga para trás. Parece que a turma naquele dia está desinteressada, está sonolenta, a turma não quer escrever, a turma não quer ler e aí você tem que rapidamente, numa fração de segundo, modificar aquilo que estava preparado. Perguntas começam a pairar sobre a mente: "Bom, eu ia escrever, e agora? O que é que eu vou fazer para eles? "Agora, jamais espere de mim joguinhos ou coisas parecidas. Ainda é na base do tradicional.

De acordo com o excerto acima, o Professor H2 compreende o significado e o sentido de ensino desenvolvido por ele e aponta o ensino enquanto processo para produto, o ensino pragmático, deixando claro que a sua aparência precede a sua essência. O docente descreve, pois, o ensino a partir do uso de técnicas e procedimentos eficientes e eficazes, apontando o ensino tradicional como "prática correta" (Liberali, 2015), ainda que afirme desenvolver práticas relacionadas às necessidades dos sujeitos.

Fica claro que o Professor H2 compreende o ensino desenvolvido para o produto sem, contudo, desenvolver a atividade como unidade processo-produto. Nesses termos, a sua compreensão de ensino apresenta-se como eclética, não apresentando as condições de promover a transformação do ensino nem dos sujeitos envolvidos, com a sua reflexão mantida no senso comum.

Observemos o excerto abaixo, quanto à reflexão, dando seguimento ao processo de compreensão do Professor H2.

Pesquisador: Você também disse na sua fala que se preocupa muito com a qualidade, né? Em outras palavras, disse que se preocupa com a qualidade, quando inclusive você compara Ensino Fundamental com Ensino Médio. Você fala que precisa de uma maneira diferente de ensino no Ensino Médio porque eles têm uma característica própria. Nesse sentido, até que ponto você considera importante refletir a respeito do ensino que você desenvolve?

Professor H2: É, cara, a gente nunca tá cem por cento certo, né? A gente sempre... talvez a minha fala reflita uma zona de conforto. Não é que eu esteja fechado a outras formas de trabalhar, né? É óbvio que o profissional responsável tem que estar sempre se permitindo refletir sobre sua prática, seja ela docente ou outra, não é? Faço isso? Faço. Mas sem abrir mão de uma essência. Por que eu sou resistente? Eu não diria fechado, mas resistente? Porque eu entendo, Pesquisador, que essa flexibilização que houve nesses últimos anos, que eu acompanhei a relação entre professores e alunos, a essa nova forma de se trabalhar na escola, ela não ajudou muito. Eu vejo os alunos cada vez piores. Antes, no meu tempo de Ensino Médio, ainda havia um certo equilíbrio numérico entre aqueles que não queriam e aqueles que queriam alguma coisa. E até mesmo aqueles que não queriam estudar, quando chegavam no terceiro ano, sabiam que o tempo estava acabando. Bom, hoje não. Hoje, a frase de um aluno de Ensino Médio é mais ou menos assim: "Ah, e é? Vou ficar reprovado? Tanto faz.". E você sabe por quê? Na minha concepção, dentre outras coisas, porque hoje se brinca de dar aula, se inventa muita marmota, se facilita muita coisa, sabe? Essa flexibilização deu aos alunos um poder que era do professor. Tem a frase de um professor famoso chamado Leandro Karnal, onde ele lamenta que, na época em que ele era aluno, o professor tinha todo poder e hoje, que ele é professor, a situação está invertida. Então, eu vou por um algoritmo, por uma sequência lógica. Se tudo que foi pregado até aqui nos trouxe a esse ponto, imagina o que nos espera daqui a cinco, dez anos.

Pesquisador: Te entendo. Mas, quando a gente fala da sua atividade de ensinar, da atividade do professor H2 de História, como é que você faz essa reflexão a respeito do ensino que você desenvolve?

Professor H2: Cara, reformula a pergunta.

Pesquisador: Você disse pra mim que é importante refletir sobre... 


\section{Professor H2: Hum rum.}

Pesquisador: ...o ensino. Como você disse nas suas palavras: o modo de ensinar. Nesse caso, você deu um exemplo mais amplo. O exemplo mais voltado pra sua prática docente, nas suas palavras, como é que você pensa o ensino que você realiza?

Professor H2: Pensa no sentido de...

Pesquisador: Refletir.

Professor H2: No sentido de qualificar?

Pesquisador: Não sei. Você disse, nas suas palavras, você disse que era importante refletir a respeito do ensino que você desenvolve. Então, como é que você faz isso? Me dê um exemplo de como é que você reflete acerca desse ensino.

Professor H2: Bom, eu procuro me avaliar de forma indireta com base naquilo que os alunos estão "fofocando" sobre mim. Porque nós sabemos que eles falam mesmo. Outra forma é através das avaliações mensais dos alunos. Mas confesso que não me pauto muito nisso porque os resultados das avaliações obedecem a inúmeras variáveis. Procuro muito observar a atenção deles durante as aulas: se os olhos estão fitos em mim e ocorre uma sucessão de perguntas, eu concluo que estou no caminho certo. Caso não, eu procuro saber o que está havendo de errado. Aí é aquela coisa mesmo de chegar em casa e literalmente pensar a respeito do problema. Partilhar experiências também é válido e a faço sempre que posso.

Pesquisador: E qual é objetivo disso? Desse seu momento de reflexão?

Professor H2: A busca da melhora, a busca de sanar os erros, a busca de tentar atingir o que todo professor quer, não é? Ser unanimidade entre os alunos. "Poxa! Lá vai o H2! Que professor joia!".

Pesquisador: (risos).

Professor H2: Mas é nesse sentido a pergunta?

Pesquisador: Sim, é. Mas há um processo de reflexão diferente por se tratar do Ensino Médio?

Professor H2: Não, é a mesma coisa. Apesar de, como eu falei, terem as suas peculiaridades, mas, no fundo, são todos alunos.

Observemos que a fala do professor H2 é de que costuma refletir a respeito do ensino que desenvolve partindo de dois momentos: o primeiro, no campo da teoria, aponta o retrocesso do ensino pelas mudanças ocorridas nos últimos anos em decorrência de teorias novas, as quais, para ele, dificultam a atividade de ensino porque restringem o empoderamento do professor, tanto quanto relaciona as mudanças que aponta com as necessidades sócio-históricas, isto é, expressa sentido fossilizado; o segundo contempla a avaliação que os alunos fazem dele e como o veem, expressando uma postura subjetiva e distanciando-se do aspecto objetivo. Nessa perspectiva, o professor expressa a reflexão técnica, não reconhece a historicidade da atividade de ensino nem o princípio processo-produto.

\section{Considerações Finais}

A realização desta investigação criou as condições para compreendermos que o significado de Ensino Eclético apresenta atributos singulares, todos construídos pelo autor a partir da empiria dos professores envolvidos na pesquisa, por meio do processo e dos procedimentos da entrevista reflexiva, quais sejam: apresenta o professor como facilitador do conhecimento, entendo o aluno como centro do ensino, caracteriza-se por ser ensino que vislumbra o processo para o produto, é totalmente a-histórico, apresenta nível de reflexão prática e não promove a transformação da vida dos envolvidos nos contextos de ensino. 
Em suma, fica claro que conseguimos alcançar o objetivo do artigo, qual seja analisar e apresentar os atributos do Ensino Eclético, objeto de escasso conteúdo bibliográfico e científico, pouco explorado nas pesquisas acadêmicas. Assim, é possível compreendermos que o presente trabalho indubitavelmente apresenta contribuição inovadora para o campo do ensino, sobretudo na contemporaneidade repleta de incertezas nesse campo.

Dado o exposto, acreditamos que esta pesquisa crie as condições para o aprofundamento do significado de ensino que hodiernamente permeia os espaços escolares de ensino mas, contraditoriamente, recebe menos atenção do que de fato merece, fazendo ser necessário o aprofundamento na pesquisa do objeto ora investigado, promovendo discussões no campo acadêmico e na esfera escola de forma global.

\section{Referências}

Afanássiev, V. G. (1982). Fundamentos de Filosofia. Progresso.

Araujo, M. P. (2010). O processo dialógico: conceito de planejamento de ensino internalizado pelos professores de ensino superior e a prática pedagógica. Dissertação (Mestrado em Educação) - Universidade Federal do Piauí, Piauí.

Araújo, N. A. \& Souza, F. D. \& Sousa; V. G. (Org) (2020). Teoria Histórico-cultural e Educação Matemática: diálogos entre a pesquisa em movimento. Ebook. https://doi.org/10.29327/523653.

Bandeira, H. M. M. \& Ibiapina, I. M. L. M. (2014). Prática Educativa: entre o essencialismo e a práxis. Revista da FAEEBA - Educação e Contemporaneidade, Salvador, 23 (42), p. 107-177.

Barddin, L. (1977). Análise do conteúdo. Edições 70.

Bonitatibus, S. G. (1991). Ensino médio: expansão e qualidade. In: MEC/SENEB/PNUD: Ensino médio como educação básica. Cadernos Seneb 4. São Paulo: Cortez; Seneb.

Bordenave, J. E. (2015). Estratégias de ensino-aprendizagem. Vozes.

Brandão, C. R. 2011). O que é educação. Brasiliense.

Brasil. Ministério da Educação. (1999). Secretaria de Educação Média e Tecnológica. Parâmetros curriculares nacionais: ensino médio. MEC/SEMTEC.

Brasil. Secretaria de Educação Básica. (2013). Formação de professores do ensino médio, etapa I - caderno I: ensino médio e formação humana integral / Ministério da Educação, Secretaria de Educação Básica. UFPR/Setor de Educação.

Carvalho, M. V. C. \& Marques, E. S. A. (2020). Educação e formação humana: práticas de enfrentamento em tempos de crise. E-book. https://www.dropbox.com/s/x2d0z8gs0dv1hgp/Livro\%20EDUCA\%C3\%87\%C3\%83O\%20E\%20FORMA\%C3\%87\%C3\%83O\%20HUMANA_2020_ebook.pdf?d1=0.pdf

Cury, C. R. J. (1991). Alguns apontamentos em torno da expansão e qualidade do ensino médio no Brasil. Ensino Médio como Educação Básica. In: MEC/SENEB/PNUD: Ensino médio como educação básica. Cadernos Seneb n. 4. Cortez; Brasília: Seneb.

Fernandes, A. G. N. F. (2011). Sentidos e Significados produzidos pelo psicólogo escolar acerca de sua atuação profissional: definindo passos e consolidando espaços. Dissertação (Mestrado em Educação). Universidade Federal do Piauí, Centro de Ciências da Educação, Programa de Pós-Graduação em Educação.

Freire, P. (1987). Pedagogia do Oprimido. Paz e Terra.

Freitas, M. T. de A. (2010). Discutindo sentidos da palavra intervenção na pesquisa de abordagem histórico-cultural. In: Freitas, M. T. A. (Org.). Fazer pesquisa na abordagem histórico-cultural: metodologias em construção. Juiz de Fora: ED. UFJF. p. 13-24.

Gatti, B. A. \& Barretto, E. S. S. \& André, M. E. D. A. \& Almeida, P. C. A. (2019). Professores do Brasil: novos cenários de formação. UNESCO.

Ghiraldelli Jr., P. (2000). Didática e teorias educacionais. DP\&A.

Ghiraldelli Jr., P. (Org.). (2000). Didática e teorias educacionais. Autêntica.

Ibiapina, I. M. L. M. \& Ribeiro, M. M. G.; Ferreira, S. (Orgs.). (2007). Pesquisa em Educação: Múltiplos olhares. Líber Livro.

Imbernón, F. (2000). A educação no século XXI: Os desafios do futuro imediato. Artes Médicas Sul.

Liberali, F. C. (2004). As linguagens das reflexões. In: MAGALHÃES, Maria Cecília Camargo (Org.). A formação do professor como profissional crítico: linguagem e reflexão.: Mercado de Letras.

Liberali, F. C. (2015). Formação crítica de educadores: questões fundamentais. Cabral Editora e Livraria Universitária.

Lima, E. (s/d). Método Eclético: a importância do uso de métodos para a leitura e escrita. http://www.webartigos.com/artigos/metodo-ecletico-a-importanciado-uso-de-metodos-para-a-leitura-e-escrita/29593/, 
Research, Society and Development, v. 10, n. 14, e561101422016, 2021

(CC BY 4.0) | ISSN 2525-3409 | DOI: http://dx.doi.org/10.33448/rsd-v10i14.22016

Machado, A. R. (Org.). (2004). O ensino como trabalho: uma abordagem discursiva. Eduel.

Mizukami, M. G. N. (1986). Ensino: As abordagens do processo. EPU.

Moraes, C. S. V. et al. (2013). Ensino Médio e formação humana integral. In: BRASIL. Secretaria de Educação Básica. Formação de professores do ensino médio, etapa I - caderno I: ensino médio e formação humana integral / Ministério da Educação, Secretaria de Educação Básica. UFPR/Setor de Educação.

Moraes, C. S. V. \& Alavarse, O. M. (2011). Ensino Médio: possibilidades de avaliação. Educação e Sociedade, 32 (116), 807-838.

Sacristán, J. G, \& Pérez Gomez, A. I. (2000). Compreender e transformar o ensino. ArtMed.

Santos, R. V. (2005). Abordagens do processo de ensino e aprendizagem. Revista Integração, 19-31

Silva, R. S. R. (2016). Caminho das pedras em espiral: mosaico dos significados e sentidos de ensinar Artes Visuais. Dissertação (Mestrado em Educação). Universidade Federal do Piauí, Piauí.

Szymanski, H. (org.) et alli. (2010). A Entrevista na Pesquisa em Educação: a prática reflexiva. Liber Livros.

Teles, F. A. R. (2008). A prática pedagógica crítico-reflexiva do professor: um processo colaborativo de (re)elaboração conceitual no Ensino Médio. Dissertação (Mestrado em Educação) - Universidade Federal do Piauí.

Vigotski, L. S. (2000). A construção do pensamento e da linguagem. Martins Fontes.

Vigotski, L. S. (2007). A formação social da mente. Martins Fontes.

Vigotski, L. S. (2008). Pensamento e linguagem. Martins Fontes.

Vigotski, L. S. (2004). Psicologia pedagógica. Martins Fontes.

Vigotski, L. S. (1994). Teoria e método em psicologia. Martins Fontes.

Weiz, T. (2009). O diálogo entre o ensino e a aprendizagem. Ática. 